\title{
HETEROGENEIDADE ESPACIAL DO FITOPLÂNCTON NA REPRESA ALAGADOS (PONTA GROSSA , PR)
}

\author{
PHYTOPLANKTON SPATIAL HETEROGENEITY IN \\ ALAGADOS RESERVOIR (PONTA GROSSA, PR)
}

\section{Rosemeri Segecin Moro ${ }^{1}$, Fernanda Ferrari ${ }^{2}$, Maria Aparecida dos Santos ${ }^{3}$, Karina Ferreira de Barros ${ }^{4}$, Jair Schmitt ${ }^{5}$}

1 Autor para contato: Universidade Estadual de Ponta Grossa - UEPG, Campus em Uvaranas, Departamento de Biologia Geral/ NUCLEAM, Ponta Grossa, PR, Brasil; e-mail: rsmoro@uepg.br; (42) 220-3126

2 Universidade Federal do Paraná, pós-graduação em Botânica, Curitiba, PR

3 Universidade Estadual de Londrina, pós-graduação em Microbiologia, Londrina, PR

4 Instituto Brasileiro do Meio Ambiente e dos Recursos Renováveis - IBAMA, Sinop, MT

5 Instituto Brasileiro do Meio Ambiente e dos Recursos Renováveis - IBAMA, Itacoatiara, AM

Recebido para publicação em 12/02/2003

Aprovado para publicação em 23/05/2003

\section{RESUMO}

A Represa Alagados (500.'W 2501'S), formada pelos rios Pitangui e Jotuva, entre os municípios de Ponta Grossa, Castro e Carambeí, é responsável por parte da captação de água de abastecimento de Ponta Grossa. Além disso, é utilizada para recreação e no seu entorno são desenvolvidas atividades agropecuárias. Com o propósito de caracterizar a comunidade fitoplanctônica, definir padrões de distribuição espacial e fornecer subsídios para planos de conservação e recuperação, foram analisadas qualitativamente amostras de seis estações, coletadas ao longo de 1999 e 2000. As estações selecionadas representam os dois tributários principais, o corpo da represa e a área da barragem. Junto ao rio Pitangui, verificou-se a menor riqueza de espécies, em relação ao padrão lótico do ambiente. As demais estações refletem ambiente lêntico, apresentando índices de diversidade, riqueza e equitabilidade similares. A estrutura da comunidade fitoplanctônica destaca dois compartimentos, o lótico e o lêntico, com progressiva transição entre eles. A zona de rio é relativamente instável, enquanto a zona lacustre parece ser capaz de amortecer os impactos oriundos das atividades e ocorrências no entorno da microbacia.

Palavras-chave: fitoplâncton, heterogeneidade espacial , represa eutrófica 


\begin{abstract}
The Alagados Reservoir ( $50^{\circ} 04^{\prime} \mathrm{W} 25^{\circ} 01^{\prime}$ 'S), is formed by the rivers Pitangui and Jotuva, near Ponta Grossa, Castro and Carambeí, and provides part of the drinking water captation for Ponta Grossa. Besides its use for recreation, the catchment area supports agricultural activities. This research intends to characterize the phytoplankton community, in order to define its spatial heterogeneity and to subsidize plans of conservation and recovery. We analyzed samples of six stations collected in the years 1999 and 2000. The stations represent the two main tributaries, the body of the reservoir and the dam zone. Close to the Pitangui river, we verified the lowest number of species with lotic characteristics. The other stations are lentic, with similar values of richness, equitability and diversity. Data analyses suggest two distinct zones in the reservoir: the lotic and the lentic, with a transitional zone in between. The river zone is relatively unstable while the lacustrine zone seems to be endure the major impacts from human activities in the basin.
\end{abstract}

Key-Words: phytoplankton, spatial heterogeneity, eutrophic reservoir

\section{Introdução}

Represas, como importantes ecossistemas artificiais de usos múltiplos, são sistemas complexos, com um padrão dinâmico, apresentando rápidas mudanças em mecanismos de funcionamento (TUNDISI, 1999). Seus usos incluem irrigação, produção de hidroeletricidade, reserva de água para abastecimento, recreação e pesca. Tais usos dependem de complexas interações e de gerenciamento adequado, o que, por sua vez, poderá ser realizado ocorrendo o acompanhamento dos padrões de comportamento do sistema e de suas alterações como resultado das ações antrópicas na bacia hidrográfica.

Para Margalef (1983), as represas constituem ecossistemas intermediários entre rios (lóticos) e lagos (lênticos), e no seu estudo devem ser consideradas as funções de força que lhes são próprias e que controlam seus processos ecológicos, pois além de estarem sujeitas a ação de forças climatológicas como precipitação, vento e radiação solar, também apresentam mecanismos específicos de circulação horizontal e vertical gerados pelo sistema de operação na barragem, e que as tornam diferentes dos outros sistemas aquáticos naturais.

A análise de represas como sistemas dinâmicos contribui para a compreensão de questões básicas em ecologia, como a sucessão de comunidades em sistemas que apresentam rápidas mudanças, padrões de colonização e efeitos de pulsos que desencadeiam uma reorganização desses sistemas em pouco tempo (TUNDISI, 1999). Seu conhecimento proporciona as bases para programas de gerenciamento da qualidade da água e das bacias hidrográficas, bem como estratégias de conservação e recuperação dos ecossistemas caracterizados.

\section{Revisão da Literatura}

A distribuição do fitoplâncton em represas varia tanto vertical (na coluna d’água) quanto espacialmente. A análise da estrutura dessas comunidades, através de indicadores como densidade celular, composição e diversidade específica, riqueza de espécies e uniformidade, permite caracterizar a compartimentalização dos ambientes. A heterogeneidade espacial do fitoplâncton tem sido estudada para a compreensão da dinâmica desses ecossistemas (POMPEO et al., 1998; FALCO e CALIJURI, 2002).

Estudos na Represa Alagados referem-se a análises hidrobiológicas (algais e bacteriológicas), e parâmetros físico-químicos, indicadores de eutrofização (MORO e VITOLA, 1991; RODRIGUES 
e PACHECO, 1997; MORO et al., 1994; MORO, 1995; WIECHETECK et al., 1999; CANAL et al., 2000).

Rodrigues e Pacheco (1997) apontaram a existência de níveis preocupantes de cianobactérias potencialmente tóxicas na Represa, especialmente Cylindrospermopsis e Dactylococcopsis, cuja abundância levou à interdição para banho e pesca nos verões de 2001/02 e 2002/03.

\section{Objetivos e Metodologia}

Este estudo objetiva caracterizar a heterogeneidade espacial do fitoplâncton em termos de densidade de organismos, riqueza, diversidade e uniformidade de espécies. Trabalha-se com a hipótese da formação de três compartimentos: zona de rio, de transição e lacustre (THORNTON et al., 1990), estabelecendo seus limites.

Espera-se fornecer subsídios para planos de conservação e/ou recuperação do manancial. Sendo local de importância sanitária, o estudo continuado da Represa Alagados é imprescindível para a produção de novas perspectivas teóricas que possibilitem uma interferência rápida e efetiva nesse ecossistema artificial.

\subsection{Caracterização da área de estudo}

A Represa Alagados (500’'W; 2501's) situa-se na divisa dos municípios de Ponta Grossa, Castro e Carambeí, e é formada pelo barramento do rio Pitangui, com a contribuição do rio Jotuva. A área inundada ao nível normal é de 7,19 Km², com extensão aproximada de 12 a 15 Km, largura média de 500m, profundidade máxima de 20m na calha do rio, e médias de 2 a $5 \mathrm{~m}$. Acumula cerca de 27,7 milhões de $\mathrm{m}^{3}$ de água e possui vazão média de $9,4 \mathrm{~m}^{3} / \mathrm{s}$, com um tempo de residência intermediário, estimado em 40 dias. Como a profundidade relativa do manancial é baixa, em torno de 0,46\%, favorece o fenômeno de circulação, devido à ação dos ventos comuns na região da represa (CANAL et al., 2000). Seu contorno é medianamente den- drítico (Fig. 1), com remansos ocupados por macrófitas como salvínia e aguapé.

A represa foi construída em 1929 para geração de energia elétrica, aproveitando o desnível existente na entrada do rio Pitangui no segundo planalto. A partir de 1969, passou-se a utilizar a represa também para captação de água para abastecimento da cidade de Ponta Grossa, respondendo atualmente por cerca de $40 \%$ do volume de água consumida na cidade, algo em torno de $31 \mathrm{mil} \mathrm{m}^{3}$ (LANGE, 1998).

O entorno da represa caracteriza-se pela exploração agropecuária. Estudos da atividade antrópica na bacia (UEPG/NUCLEAM, 2002) apuraram que a microbacia do Jotuva caracteriza-se por pequenas propriedades, onde predominam aviários e suinocultura. Na microbacia do Pitangui, a montante da represa, o sistema de grandes propriedades prioriza a agricultura mecanizada de exportação e, secundariamente, a pecuária de corte. A represa é utilizada também como área de lazer, havendo em suas margens várias casas de veraneio e dois clubes náuticos. Capri (1999) diagnosticou uma série de problemas ambientais decorrentes da ação antrópica no local.

O clima da região é do tipo Cfb (úmido subtropical com chuvas bem distribuídas ao longo do ano), com pluviosidade média em torno de $1.373 \mathrm{~mm}$ anuais, com um período chuvoso ligeiramente acentuado de outubro a março e inverno relativamente seco, com temperaturas médias entre $15^{\circ} \mathrm{C}$ e $17^{\circ} \mathrm{C}$ (MAACK, 1968). A umidade relativa média do ar é de 76,8\% com ventos suaves a moderados, entre 20 a $50 \mathrm{Km} / \mathrm{h}$.

\subsection{Amostragem e análises}

A escolha de seis estações de coleta (Fig. 1) foi feita por Wiecheteck et al. (1999) através de geoprocessamento IDRISI, assim definidas:

Estação 1 - próxima ao tributário Pitangui; estação 2 - próxima ao tributário Jotuva; estação 3 - no primeiro terço da represa; estação 4 - no terço intermediário da represa; estação 5 - no terço final da represa, em frente ao Iate Clube; estação 6 - próxima à barragem. 
As coletas foram realizadas quinzenalmente por Wiecheteck et al. (1999) de janeiro de 1999 a maio de 2000, através de arrasto superficial com rede de plâncton (45mm de malha) e em garrafa de Van Dorn, fixadas com lugol acético. Encontramse incorporadas ao acervo do herbário HUEPG, sob números 199 a 519.

A densidade de organismos foi determinada em contagens na câmara de Sedgwick Rafter e a análise qualitativa foi feita em lâminas semipermanentes sob microscopia ótica. As unidades de con- tagem foram células, colônias, tricomas, filamentos e cenóbios. As determinações foram feitas até o nível de classe, através de comparações com floras básicas de Bourrely (1972, 1981, 1985) e Bicudo e Bicudo (1970).

Foram calculados os índices de diversidade de Shannon-Wienner ( $H^{\prime}$ ) e equitabilidade de Pielou (J') a partir de riqueza de espécies (S) e sua freqüência absoluta utilizando-se os programas Statecol (1984) e Statistica para Windows (1993).

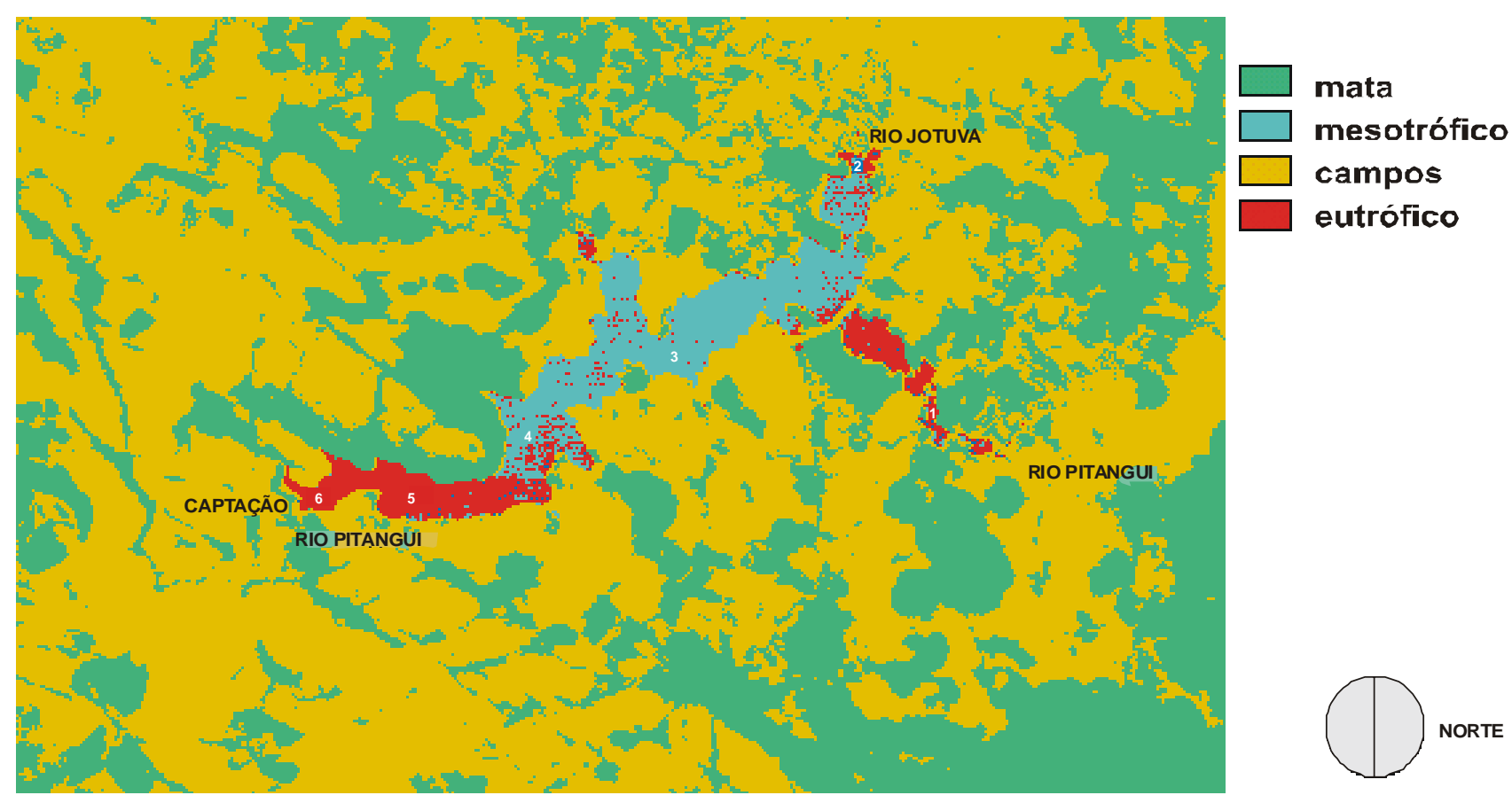

Figura 1 - Foto de satélite da Represa, com as seis estações de coleta sinalizadas. Fonte: Wiecheteck et al. (1999)

\section{Resultados e discussão}

A densidade absoluta de organismos fitoplanctônicos variou de zero (na est. 1) a 60.000 org./ml (na est. 6). As estações 1, 2 e 3 apresen- taram em média 7.500 org./ml; enquanto as estações 4, 5 e 6 apresentaram média mais abundante, de 12 a 16.000 org./ml (Fig. 2). Percebe-se que blooms de algas tendem a ocorrer nas estações 4 , 5 e 6. 


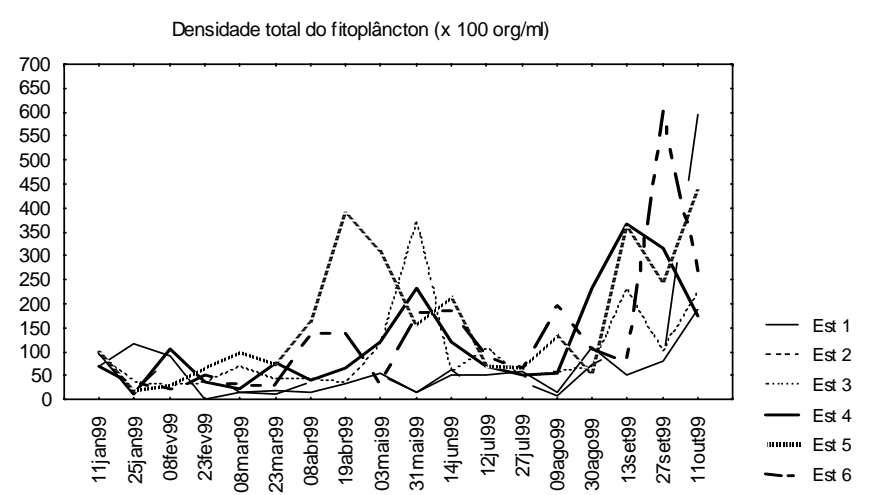

Figura 2 - Variação da densidade total do fitoplâncton da Represa Alagados nas seis estações amostradas.

A tabela 1 apresenta os valores médios e desvio padrão dos valores de riqueza (S), diversidade (H') e equitabilidade (J') observados no período amostral em todas as estações. As médias da riqueza variaram de 9,5 a 12,9; as da diversidade variaram de 1,36 a 1,51; e as da equitabilidade, de 0,56 a 0,67 .

Tabela 1- Valores médios de Riqueza, Diversidade e Equitabilidade do fitoplâncton nas estações de coleta no período amostrado.

\begin{tabular}{c|c|c|c|c|c|c}
\hline Estações & \multicolumn{2}{|c|}{$\begin{array}{c}\text { Riqueza } \\
\text { (S) }\end{array}$} & \multicolumn{2}{c|}{$\begin{array}{c}\text { Diversidade } \\
\text { (H') }\end{array}$} & \multicolumn{2}{|c}{$\begin{array}{c}\text { Equitabilidade } \\
\text { (J') }\end{array}$} \\
\cline { 2 - 7 } & $\mathrm{X}$ & $\sigma$ & $\mathrm{x}$ & $\sigma$ & $\mathrm{x}$ & $\sigma$ \\
\hline \hline 1 & 9,5 & 7,6 & 1,36 & 0,84 & 0,61 & 0,33 \\
2 & 11,2 & 7,5 & 1,51 & 0,77 & 0,67 & 0,27 \\
3 & 11,3 & 5,9 & 1,46 & 0,73 & 0,59 & 0,31 \\
4 & 12,9 & 6,8 & 1,44 & 0,64 & 0,56 & 0,23 \\
5 & 12,0 & 5,5 & 1,42 & 0,70 & 0,60 & 0,24 \\
6 & 12,8 & 6,8 & 1,44 & 0,65 & 0,58 & 0,23 \\
\hline
\end{tabular}

A riqueza média de espécies aumenta progressivamente da Estação 1 até a Estação 6, considerado o período amostrado como um todo, enquanto as médias de diversidade específica e equitabilidade mantêm certa regularidade (Fig. 3).

Sistemas lóticos caracterizam-se por apresentar condições ambientais que estão variando no espaço e no tempo, com maior turbulência e menor transparência da água, e redução da zona fótica. As comunidades desse sistema são geralmente perifíticas, sendo pouco comuns as espécies verdadeiramente planctônicas. Portanto, à medida que o ambiente torna-se lêntico, a densidade (Fig. 2) e riqueza fitoplanctônicas (Fig. 3) tendem a aumentar.

A diversidade em geral é associada diretamente à estabilidade da comunidade, e inversamente ao grau de alteração do sistema (MARGALEF, 1983). No entanto, Ferreira e Rocha (1988) consideram a riqueza de espécies o mais importante índice de discriminação ambiental, comparando-se ambientes com distintas condições de eutrofização.

Na estação 5 é observada pequena queda de riqueza, e ligeiro aumento da equitabilidade, o que pode estar relacionado ao impacto da ocupação urbana na margem esquerda da represa.

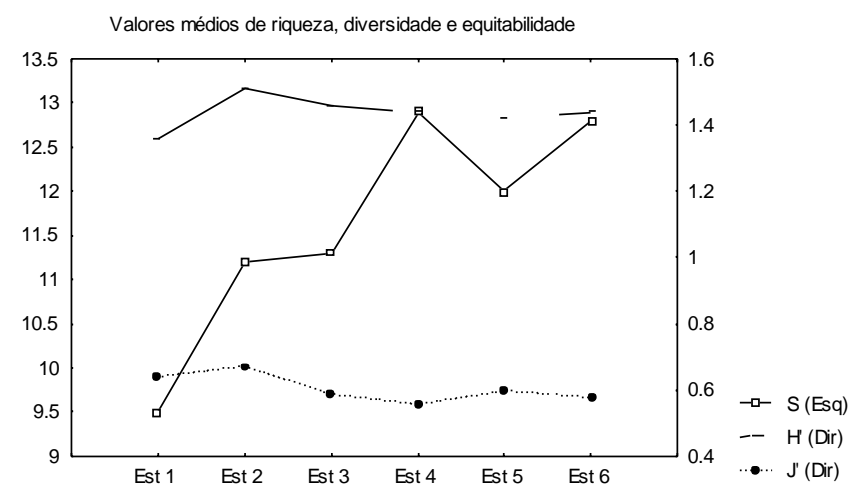

Figura 3 - Comparação entre as médias de riqueza de espécies (S), diversidade específica (H’) e equitabilidade (J') nas seis estações durante todo o período amostral.

Devido à pouca amplitude de variação no índice de diversidade de Shannon-Wienner, procedeuse a uma análise de agrupamento de Ward (Fig. 4). Percebeu-se que as estações escolhidas por geoprocessamento aproximaram-se bastante dos grupamentos naturais: (a) o ambiente lótico formado pelo pré-represamento do rio Pitangui (Estação 1) ocasiona uma distribuição de organismos diferenciada das demais estações, lênticas; (b) as estações 5 e 6 , correspondentes ao terço final da represa, com maior profundidade da lâmina d’água, são as mais símiles 
entre si; (c) um terceiro grupo é formado pelas estações 2, 3 e 4, com profundidades variáveis e, talvez, certa similaridade na dinâmica da coluna d’água.

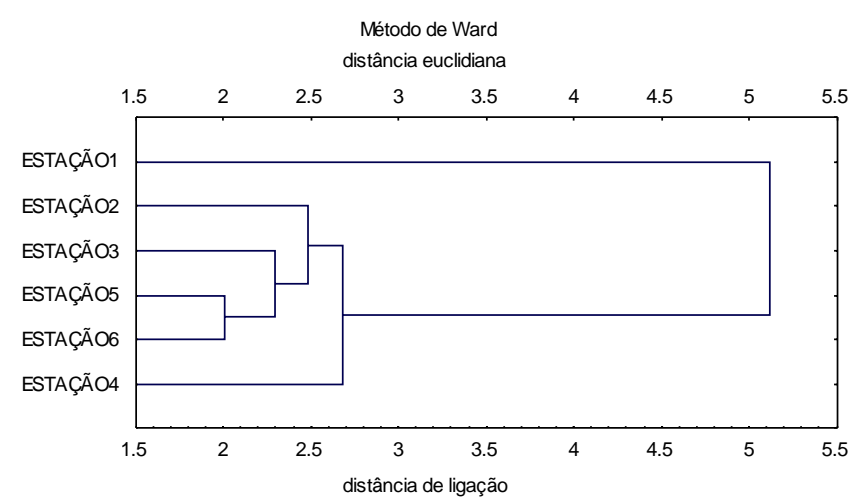

Figura 4 - Análise de agrupamento dos valores observados de diversidade específica (H’) nas seis estações durante o período amostral.

Os táxons foram determinados até o nível de Classe, com representantes mais abundantes nas
Classes Bacillariophyceae, Chlorophyceae/ Zygnemaphyceae, Cyanophyceae e Euglenophyceae. As duas primeiras são mais importantes em termos de freqüência de organismos e demonstram comportamento competitivo pelos mesmos recursos. Bacillariophyceae predominam de abril a dezembro e Chlorophyceae/ Zygnemaphyceae, de dezembro a março. Cyanophyceae desenvolvem-se melhor no verão, com a estratificação térmica da represa. As Classes Cryptophyceae, Chrysophyceae e Dinophyceae não foram representadas graficamente porque tiveram aparições apenas pontuais nas estações e serão estudadas em outro trabalho.

Analisando-se qualitativamente a variação das principais classes do fitoplâncton, percebem-se dois padrões de distribuição espacial na Represa (A e B). Há maior variação das freqüências das classes de algas e sucessões rápidas dos organismos nas estações 1 e 2 (padrão A), na região de desembocadura dos rios Pitangui e Jotuva (Figs. 5 e 6).

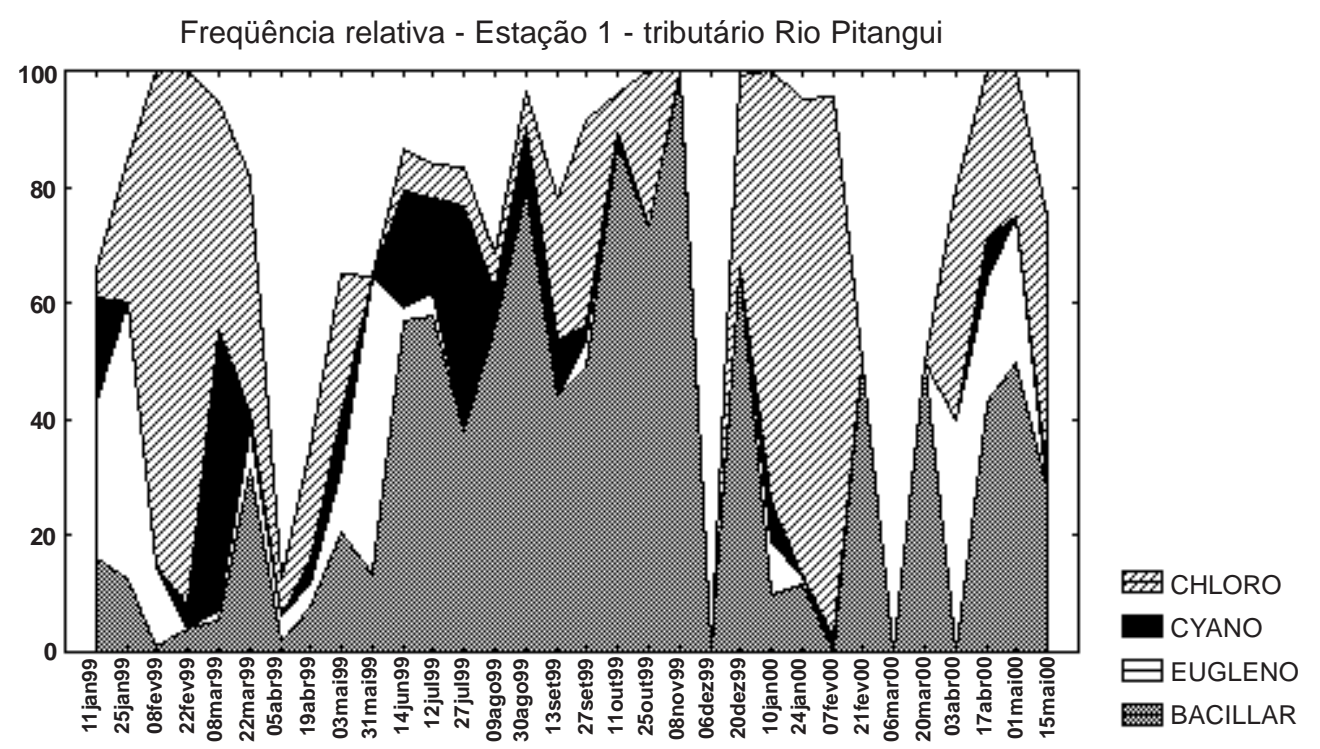

Figura 5 - Padrão A, onde a freqüência relativa das principais Classes de algas na Estação 1 (entrada do Pitangui) sofreu alterações abruptas no período amostrado. 
Freqüência relativa - Estação 2 - tributário Rio Jotuva

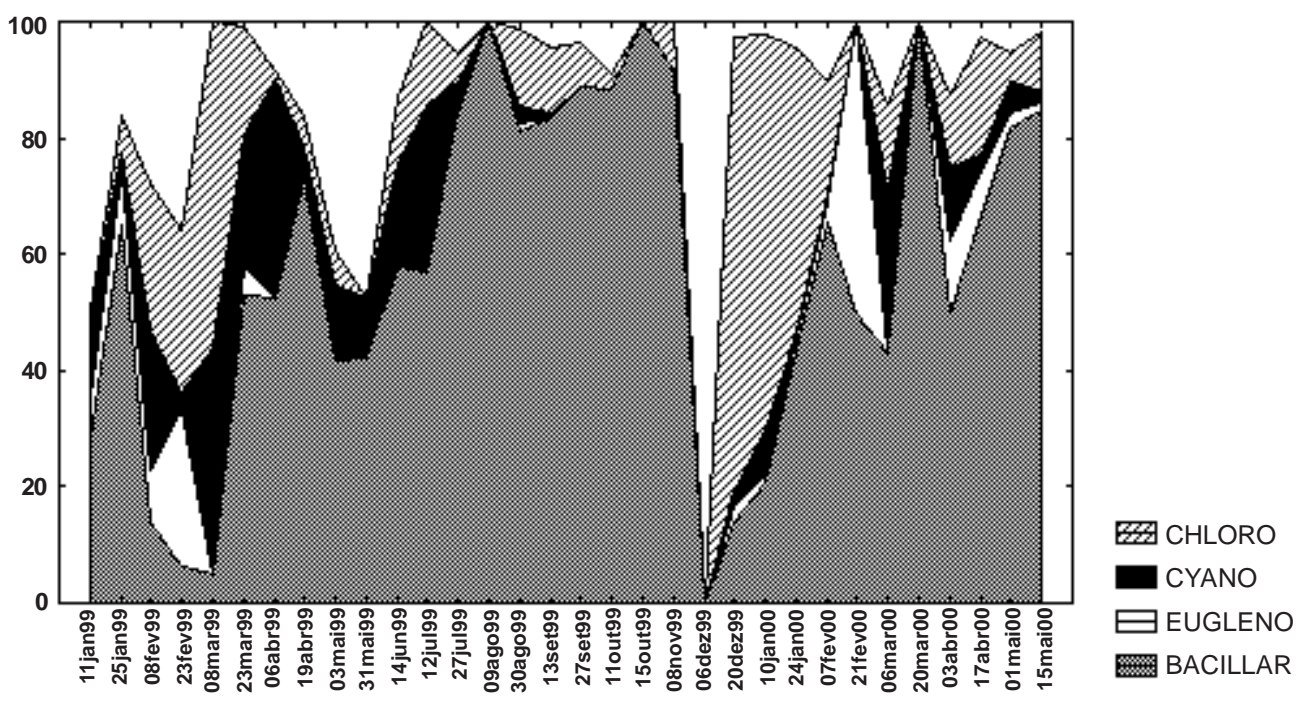

Figura 6 - Padrão A, onde a freqüência relativa das principais Classes de algas na Estação 2 (entrada do Jotuva), sofreu uma variação pouco menor no período amostrado.

Embora o padrão A esteja associado a um ambiente de características lóticas, a localização das estações próximas aos tributários difere entre si substancialmente no sentido de que a Estação 1 situa-se numa área de pré-represamento anterior à Ponte Preta; enquanto a Estação 2, localiza-se após o pré-represamento proporcionado pela estrada de Catanduvas. Nas pré-represas ocorre a retenção de nutrientes e sedimentos, que minimizam seus efeitos relacionados ao tratamento de água e à vida útil dos reservatórios. Nessas estações a ocorrência de Euglenophyceae foi maior, o que pode ser explica- do pela presença de macrófitas e por um maior aporte de matéria orgânica através dos tributários.

Na estação 3 (Fig. 7), a variação das freqüências mais regular demonstra a transição gradual para ambientes de águas mais profundas das outras estações.

As estações 4, 5 e 6 refletem o ambiente predominantemente lêntico (padrão B), sujeito a blooms de Cyanophyceae, especialmente nos meses de janeiro a abril, favorecidos pela maior estabilidade da coluna d'água em dias de altas temperaturas e pouco vento.

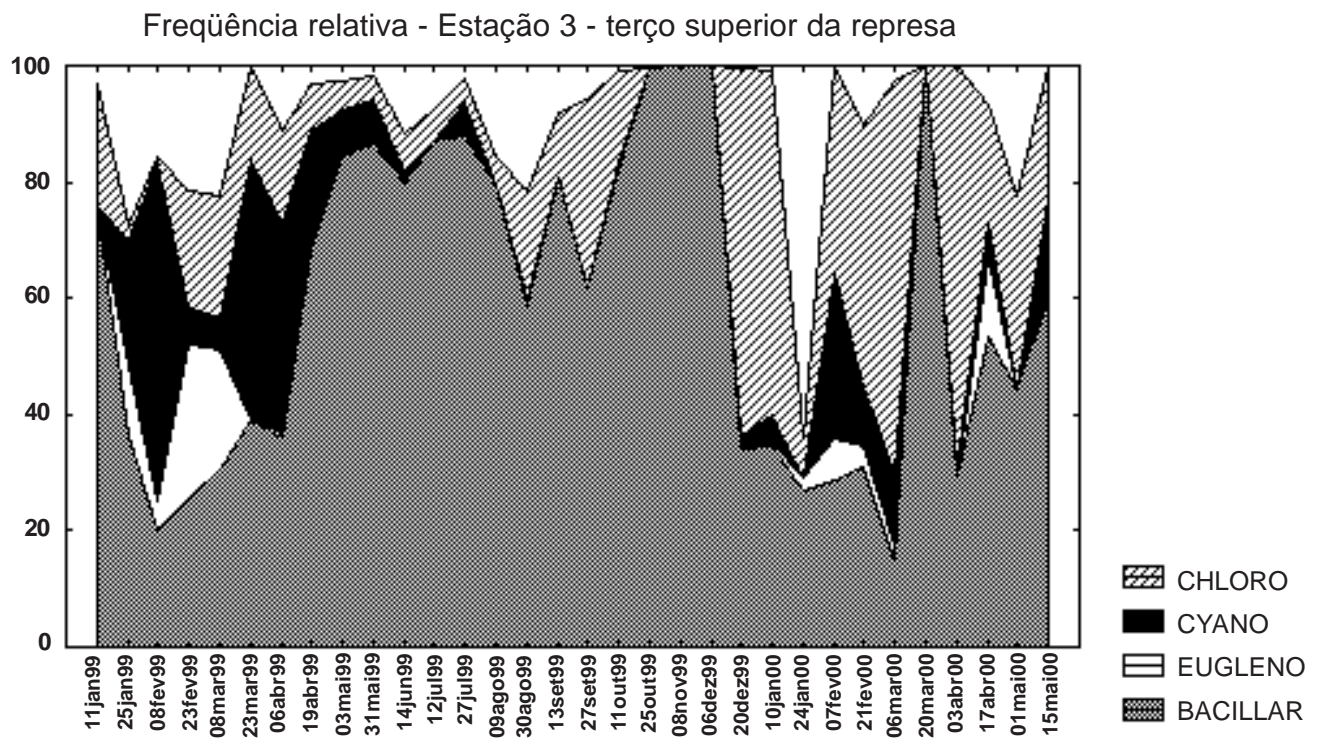

Figura 7 - Transição na Estação 3 (terço superior da Represa) entre ambientes mais rasos e mais profundos. 


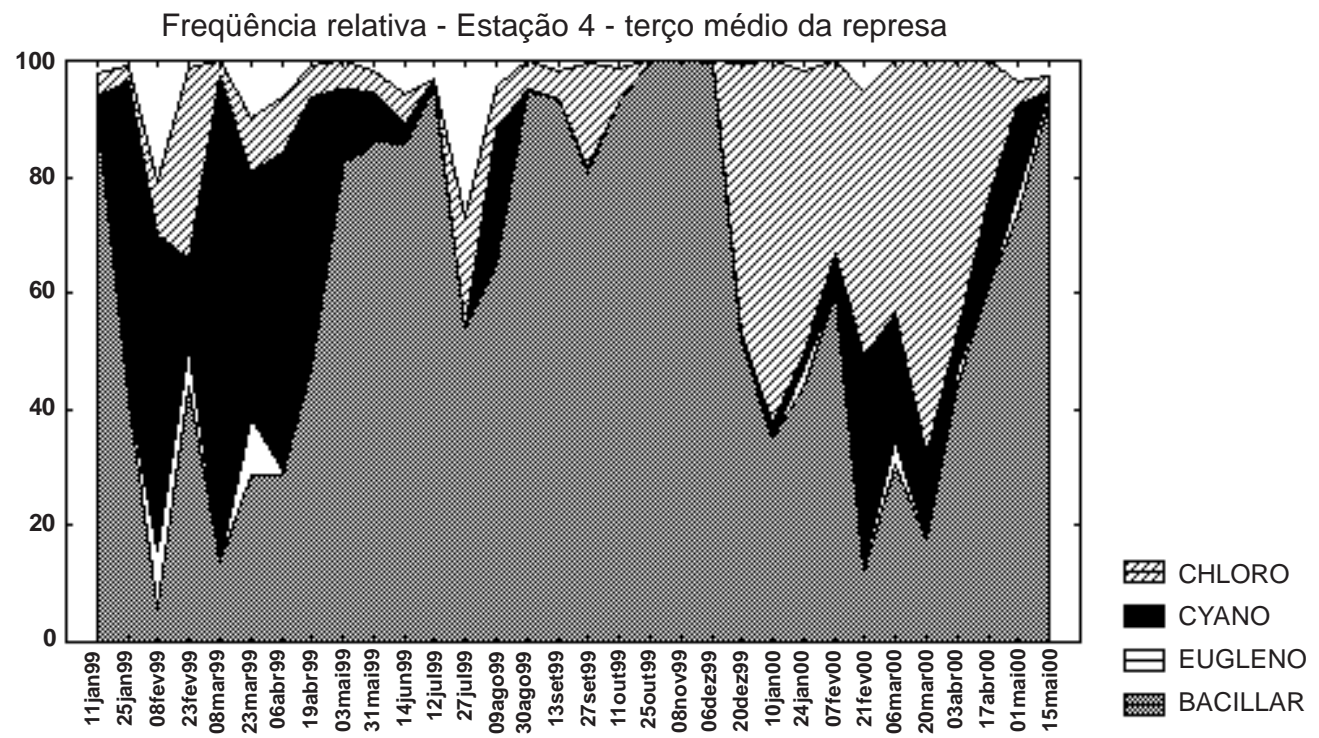

Figura 8 - Padrão B, onde a freqüência das Classes de algas na Estação 4 (terço médio da Represa) reflete o ambiente lêntico, e a tendência de formação de blooms de cianobactérias no verão.

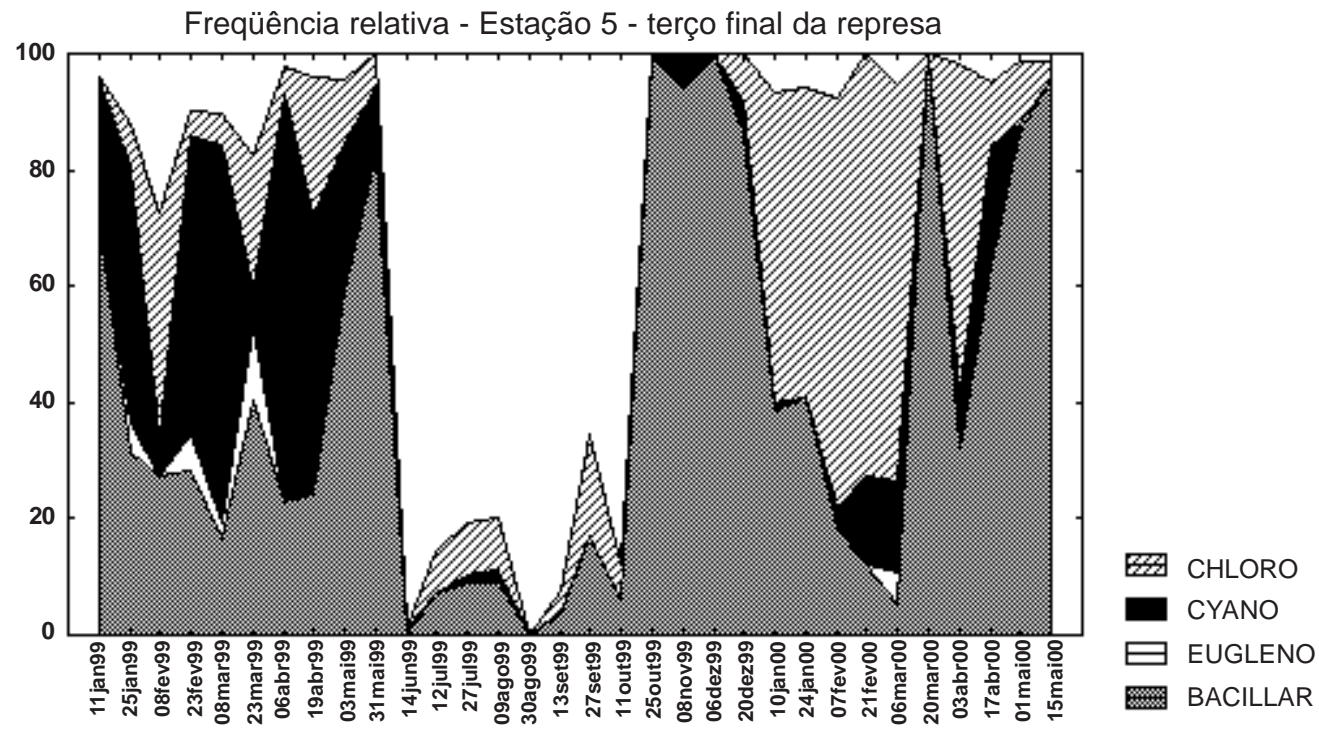

Figura 9 - Interrupção parcial do Padrão B na Estação 5 (terço médio da Represa). 


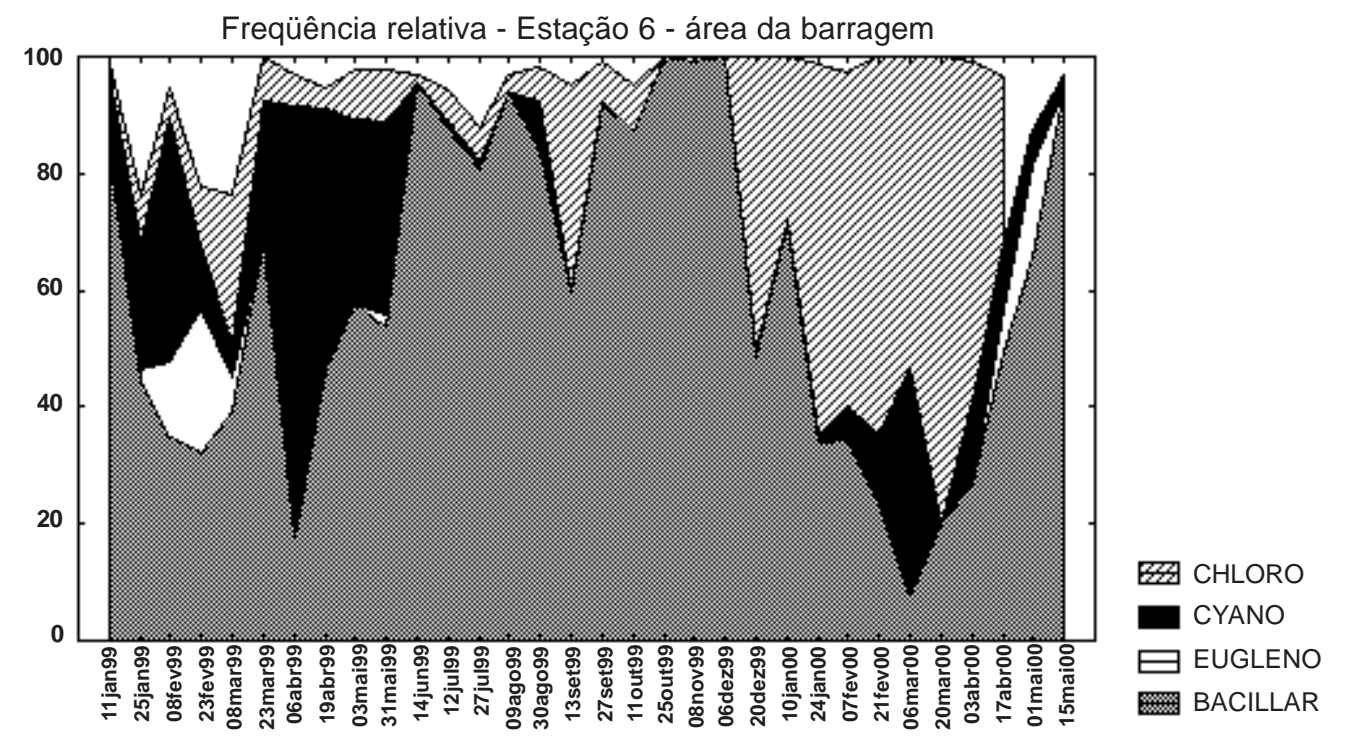

Figura 10 - Retomada do Padrão B na Estação 6 (próxima á barragem).

Com relação a coliformes totais e fecais, Wiecheteck et al. (1999) e Canal et al. (2000) enquadraram as Estações 1 e 2 na Classe 3 do CONAMA 20/86. Seus resultados apontaram importante entrada de material orgânico através dos tributários, sendo os pontos de maior preocupação ambiental. As Estações 3, 4 e 5 estão na Classe 2, e a Estação 6 na Classe 1. Quanto a DBO, a represa é enquadrada na classe 4 da Resolução CONAMA, representando o principal parâmetro que indica que a represa sofre um processo de eutrofização. Os autores alertaram que cuidados com a preservação do manancial devem ser contínuos, visando a preservação da qualidade da água para abastecimento.

\section{Conclusões}

A escolha de estações de coleta por geoprocessamento foi bastante satisfatória ao selecionar grupamentos naturais, discriminados pelos valores de diversidade específica.

Com relação à freqüência relativa de classes e estrutura da comunidade fitoplanctônica, a represa de Alagados apresenta heterogeneidade espacial horizontal.
As estações 1 e 2 podem ser caracterizadas como zona de rio, enquanto as estações 4, 5 e 6 são mais representativas de zona lacustre. A estação 3 representa uma zona de transição entre os compartimentos lótico e lêntico. O primeiro é relativamente instável, e o segundo parece ser capaz de amortecer os impactos oriundos das atividades e ocorrências no entorno da microbacia. Há, no entanto, diferenças na dinâmica do fitoplâncton nos ambientes de pré-barragem. Ações de recuperação e preservação devem ser diferenciadas para cada compartimento, levando em conta a velocidade de resposta de cada um.

Os maiores impactos parecem provenientes das atividades econômicas do entorno, através dos tributários, porém até a região da barragem o tempo de residência da água é suficiente para a depuração da água, em função do regime de ventos e profundidade da represa, que permitem a circulação da coluna de água. O processo de recuperação é perturbado pela presença de casas de veraneio na margem da represa. Medidas com relação a essa ocupação, e disposição adequada de resíduos da área de entorno podem aliviar a pressão sobre a área de captação, aumentando o tempo de vida útil da represa enquanto manancial para abastecimento. 
Agradecimentos

À SANEPAR, pelo apoio nas coletas. À Profa. GiovanaWiecheteck, da UEPG pela cessão das amostras. Ao CNPq pela concessão de bolsas de iniciação científica.

\section{REFERÊNCIAS}

1 BICUDO, C. E. M.; BICUDO, R. M. T. Algas de águas continentais brasileiras. São Paulo: Fund. Bras. para Desenv. Ens. Cienc., 1970.

2 BOURRELY, P. Les algues d'eau douce. Paris: Boubée, 1972. v. 1: Les Algues vertes.

3 BOURRELY, P. Les algues d'eau douce. Paris: Boubée, 1981. v. 2: Les Algues jaunes et braunes.

4 BOURRELY, P. Les algues d eau douce. Paris: Boubée, 1985. v. 3: Les Algues bleues et rouges.

5 CANAL, M.; SCHMITT, J.; MORO, R. S.;WIECHETECK, G. K. Monitoramento da qualidade da água da Represa do Alagados. In: ENCONTRO ANUAL DE INICIAÇÃO CIENTÍFICA, 9, 2000, Ponta Grossa. Resumos .... p.592-593.

6 CAPRI, L. Diagnóstico preliminar das irregularidades ambientais decorrentes da ação antrópica praticadas na Represa de Alagados, Ponta Grossa, PR. Ponta Grossa, 1999. 78 p. Monografia (Especialização em Geografia Urbana e Análise Ambiental) Universidade Estadual de Ponta Grossa.

7 FALCO, P. B.; CALIJURI, M. C. Longitudinal phytoplanktonic community distribution in a tropical reservoir (Americana, São Paulo, Brazil). Acta Limnol. Bras., v. 14, n. 2, p. 27-37, 2002.

8 FERREIRA, C. J. A.; ROCHA, A. J. A. Estudo comparativo de comunidades fitoplanctônicas e o uso de diversidade como discriminante ambiental. Acta Limnol. Bras., v. 11, p. 447468, 1988.

\section{LANGE, F. L. P. Os Campos Gerais e sua Princesa.} Curitiba: COPEL, 1998.

10 MAACK, R. Geografia física do Paraná. 2. ed. FUNDEPAR: Curitiba, 1968.
11 MARGALEF, R. Limnología. Barcelona: Omega, 1983.

12 MORO, R. S.; VITOLA, C. R. R. Estudos limnológicos na Represa Alagados, Ponta Grossa, PR. Guairacá (UNICENTRO), Guarapuava, n. 8, p. 167-177, nov. 1991.

13 MORO, R. S.; GARCIA, E.; OLIVEIRA JUNIOR, H. F. de. Análise taxonômica de diatomáceas (Bacillariophyceae) na Represa Alagados, Ponta Grossa, Paraná, Brasil (exclusive cêntricas). Iheringia, sér. Botânica, Porto Alegre, v. 45, p. 519, ago. 1994.

14 MORO, R. S. Diatomáceas cêntricas (Chrysophyta Bacillariophyceae) da Represa Alagados - Ponta Grossa - PR - Brasil. Publicatio UEPG, v. 3, n. 3, p. 91-102, 1995.

15 POMPEO, M. L. M. et al. Heterogeneidade espacial do fitoplâncton no Reservatório de Boa Esperança (MaranhãoPiauí, Brasil). Acta Limnol. Bras., v. 10, n. 2, p. 101-113, 1998.

16 RODRIGUES, E. M.; PACHECO, C. R. R.V. Utilização de corpos d’água com superdesenvolvimento de cianobactérias (algas azuis): implicações e cuidados quando da liberação de suas toxinas em águas de abastecimento. Sanare, v. 7, n. 7, jan./jun. 1997.

17 PHOENIX SOFTWARE ASSOCIATES LTDA. Statecol.sle Software GW-Basic 2.02. 1984. 1 disquete 31/2 pol.

18 STATSOOFT INC. Statistica para Windows 4.2. 1993. 6 disquetes $31 / 2$ pol.

19 THORNTON, K.W.; KIMMEL, B.L.; PAYNE, F. E. Reservoir limnology: ecological perspectives. New York: John Wiley \& Sons, 1990.

20 TUNDISI, J. G. Reservatórios como sistemas complexos. In: HENRY, R. Ecologia de Reservatórios: estrutura, função e aspectos sociais. Botucatu: FUNDBIO/FAPESP, 1999. Cap.1, p. 19-38.

21 UEPG/ NUCLEAM. Bacia hidrográfica do manancial Alagados. Ponta Grossa, 2002. Relatório técnico (CD-ROM).

22 WIECHETEK, G. K.; MORO, R. S.; SCHMITT, J.; SALDANHA, J. R. Biomonitoramento da qualidade de água de abastecimento de Ponta Grossa, PR. In: JORNADA CIENTÍFICA DE PESQUISA SOCIAL, 1., 1999, Ponta Grossa. Anais... Ponta Grossa: UEPG, 1999. 1 CD-ROM 